\title{
Host Nutritional Status as a Contributory Factor to the Remodeling of Schistosomal Hepatic Fibrosis
}

\author{
Eridan M Coutinho/ ${ }^{+}$, Andréia F Barros, Aryon Barbosa Jr*, Sheilla A Oliveira, \\ Luciana M Silva*, Roni E Araújo, Zilton A Andrade*
}

\author{
Laboratório de Imunopatologia, Centro de Pesquisas Aggeu Magalhães-Fiocruz, Caixa Postal 7472, 50670-420 Recife, PE, Brasil \\ *Laboratório de Patologia Experimental, Centro de Pesquisas Gonçalo Moniz-Fiocruz, Salvador, BA, Brasil
}

Weaning Swiss mice were percutaneously infected with 30 cercariae of Schistosoma mansoni and submitted to a shifting either from a deficient to a balanced diet or vice-versa, for 24 weeks. The nutritional status was weekly evaluated by measurements of growth curves and food intake. Hepatic fibrosis and periovular granulomas were studied by histological, morphometric and biochemical methods. All mice fed on a deficient diet failed to develop periportal "pipestem" fibrosis after chronic infection. An unexpected finding was the absence of pipestem fibrosis in mice on normal diet, probably related to the sample size. The lower values for nutritional parameters were mainly due to the deficient diet, rather than to infection. Liver/body weight ratio was higher in "early undernutrition" group, after shifting to the balanced diet. Volume density and numerical density of egg granulomas reached lowest values in undernourished animals. The amount of collagen was reduced in undernourished mice, attaining higher concentrations in well-fed controls and in "late undernutrition" (balanced diet shifted to a deficient one), where collagen deposition appeared increased in granulomas. That finding suggested interference with collagen degradation and resorption in "late" undernourished animals. Thus, host nutritional status plays a role in connective tissue changes of hepatic schistosomiasis in mice.

Key words: Schistosoma mansoni - undernutrition - hepatic fibrosis

The characteristic morphologic picture of schistosomal periportal fibrosis in man has adequately been described by Symmers (1904) long ago, but its pathogenesis remains to be satisfactorily explained. Although the pathogenesis and pathology of so-called Symmer's fibrosis have been extensively studied with human material by many investigators (Bogliolo 1957, Prata \& Andrade 1963, Andrade 1965, Andrade \& Bina 1983), the need for investigations in a good experimental host is obvious. The lesion has been reproduced in several experimental models, including monkeys (Sadun et al. 1970, Lichtenberg et al. 1971), rabbits infected with Schistosoma japonicum (Cheever et al. 1980) and mice (Warren 1966, Andrade 1987, Andrade \& Cheever 1993, Henderson et al. 1993, Andrade et al. 1997). Albino Swiss mice submitted to relatively mild (1-2 worm pairs) and prolonged infections with Schistosoma mansoni (16 weeks or more) develop, in 30 to $50 \%$ of them, a lesion similar to human Symmer's fibrosis, as a consequence of a massive and continuous deposition of eggs along the dilated intra-hepatic venous portal branches (Andrade 1987).

The mice exhibit hepatic schistosomal lesions of two different morphological patterns: (1) relatively extensive hepatic fibrosis with conglomerates of egg granulomas

${ }^{+}$Corresponding autor. Fax: +55-81-3453.2449. E-mail: ecoutinho@cpqam.fiocruz.br

Received 20 May 2003

Accepted 8 October 2003 along dilated portal branches within portal spaces, with increased periportal connective tissue, mimicking the Symmer's fibrosis of man; (2) granulomatous inflammation, with scattered periovular granulomas distributed throughout the hepatic tissue (Andrade et al. 1997). Henderson et al. (1993) were able to detect immunological differences in chronically infected $\mathrm{CBA} / \mathrm{J}$ male mice exhibiting either one of the morphologic patterns above described. These differences regarded distinct anti-SEA idiotypic antibody profiles.

Previous investigation from this laboratory showed that mice with mild, 16-week old $S$. mansoni infection, maintained on a low-protein diet, completely failed to develop "pipe-stem" fibrosis of the liver, different from the well-nourished controls (Coutinho et al. 1997).

In an attempt to find out which factors or mechanisms are possibly involved in producing different schistosomiasis pathology in well-nourished mice, as contrasted to undernourished ones, the role of the nutritional status was investigated as related to the dynamics of collagen formation and resorption during experimental hepatic schistosomiasis.

\section{MATERIALS AND METHODS}

Animals and infection - Male albino Swiss mice (21 day old), weighing 11 to $13 \mathrm{~g}$, were kept in individual wire bottom cages. Water and food were provided ad libitum. All animals received humane care in compliance with the guidelines of the Animal Care and Use Committee of the Oswaldo Cruz Foundation (Fiocruz). Each mouse was exposed to 30 cercariae (percutaneous route) of the $\mathrm{BH}$ strain (Belo Horizonte, Brazil) of S. mansoni, four weeks after ingesting the first diet, according to its respective group. The cercariae were obtained from laboratory raised 
and infected Biomphalaria glabrata. Infection lasted 24 weeks and the effects of diet intake were followed for 28 weeks.

Diets - Undernutrition was induced in mice by feeding them with a multideficient and essentially low-protein diet (7-8\% protein), planned to simulate that usually ingested by low-income individuals living in endemic areas of Manson's schistosomiasis in Northeast Brazil (Coutinho et al. 1997) and is thus referred to as regional basic diet (RBD). Control diet (NUVILAB) was a pelleted commercial balanced chow for mice produced by Nuvital Nutrientes Ltda (Colombo, PR, Brazil), with $22 \%$ protein content.

Experimental groups - Mice were divided into four different groups, with 11 animals in each group, except for one control group (CG3 with seven animals).

Group G1, "early undernutrition" - RBD was offered during 16 weeks and then replaced by NUVILAB for a further 8 weeks period.

Group G2, "late undernutrition" - Animals were maintained on NUVILAB for 16 weeks, which was then shifted to RBD for 8 weeks.

Group CG3, "long-lasting" undernutrition (Controls for group G-1) - The RBD-diet was offered throughout the whole experiment.

Group CG4, "long-lasting" normal feeding (Controls for group G-2) - Animals maintained on NUVILAB during the whole time of experiment.

Evaluation of nutritional status - Body weight and food consumption were the parameters used to evaluate the nutritional status of the animals. The body weight was weekly recorded and determinations on food intake were pursued every day. The experimental model used has extensively been studied in previous investigations (Coutinho 1980, Teodósio et al. 1990, Coutinho et al. 1992, 1997).

Morphological studies - Twenty-four weeks after cercarial exposure, the animals were sacrificed by cervical dislocation. The livers were removed, rinsed with phosphate buffered saline (PBS), weighed and divided into several portions. Spleen was also removed, rinsed in PBS and weighed. One section of the liver was fixed in Bouin's fixative and/or in buffered (pH 7.4) $10 \%$ formaldehyde, for histologic examination. Tissue was embedded in paraffin and the $5 \mu \mathrm{m}$ thick sections obtained were stained with haematoxylin-eosin and picrosirius-red method for collagen (Junqueira et al. 1979). Another portion of the liver was placed in $4 \%$ potassium hydroxide for egg counting (Cheever 1970).

Morphometry - Randomly sampled $5 \mu \mathrm{m}$-thick liver histological sections, stained with picrosirius-red for collagen, were examined by semiautomatic morphometry using the LEICA Q500 MC Image Processing and Analysis System (Leica Cambridge, Cambridge, England). For morphometric measurements a total sectional area of 6.6 $\mathrm{mm}^{2}$ per animal was evaluated. All periovular granulomas were included. A spherical shape and normal size distribution were assumed. The following granuloma parameters were calculated: size, volume density, and numerical density. The granuloma volume density was calculated as the quotient of the total granuloma profile area to the total sectional area studied per animal. The number of granulomas per unit volume of liver was assessed by applying the Weibel's formula. The sectional area of the fibrous tissue, red stained, was directly measured and calculated as a percentage of the total area examined, as previously described (Coutinho et al. 1997, Barbosa Jr. 2001).

Biochemical study - Pieces of the liver were frozen at $70^{\circ} \mathrm{C}$ for determination of collagen, measured as hydroxyproline by the spectrophotometric method B of Bergman and Loxley (1963). Hydroxyproline levels were corrected for intensity of infection by dividing total hepatic hydroxyproline (without correction for hydroxyproline levels in uninfected mice) by the number of $S$. mansoni eggs in the liver. Calculations for this correction were made with help of a simplified electronic spread sheet elaborated by Cheever et al. (1987) and used in subsequent papers.

Statistical analysis - Data were analyzed with the Student's t-test when appropriate or by one-way analysis of variance (when comparing means of more than two groups) and Mann-Whitney's test. Pearson's linear correlation was also determined. Values of $p<0.05$ were taken to be significant.

\section{RESULTS}

Nutritional status - Mice submitted to early undernutrition (G1) and/or late undernutrition (G2) showed diverging growth curves, with higher values for ingestion during periods of feeding on the commercial balanced diet. During this period of time, the mean body weight in group G2 fell from $35.2 \mathrm{~g}$ to $30 \mathrm{~g}$, while in group G1 it grew up from $22.7 \mathrm{~g}$ to $34.9 \mathrm{~g}$.

When growth curves of group G1 and CG3 (controls) are compared, the benefits on the nutritional status of the mice due to shifting from RBD to NUVILAB could be clearly observed. Mean body weight in underfed control animals (CG3) dropped to 19.1g at the end of the experiment, while mice shifting from the deficient to the balanced diet reached a mean body weight of $34.9 \mathrm{~g}$ at the same time point.

Animals from groups $\mathrm{G} 2$ and CG4 (controls) showed similar ascending growth curves until the moment of shifting the diet. Since then, body weights from mice in group $\mathrm{G} 2$ decreased progressively, reaching a mean value of $30 \mathrm{~g}$ at the end of the experiment, as compared to $36.2 \mathrm{~g}$ detected for control mice (CG4) fed exclusively on a balanced diet (Fig. 1).

Measurements on food intake over the 24 weeks of infection showed a good correlation with body weight values.

\section{Morphological studies}

Gross pathology - Liver and spleen weights, as related to total body weights, were obtained at the time of sacrifice. Mean liver weight was significantly higher (5.81 \pm SEM 0.24) for "early undernourished" mice (G1) as compared to "late undernourished" (G2) animals (4.82 \pm SEM 0.23). However, regarding spleen weight no statistically significant difference was detected between these two groups $(0.66 \pm$ SEM 0.06 and $0.53 \pm$ SEM 0.04 , respectively). Results referring to crossings between the 


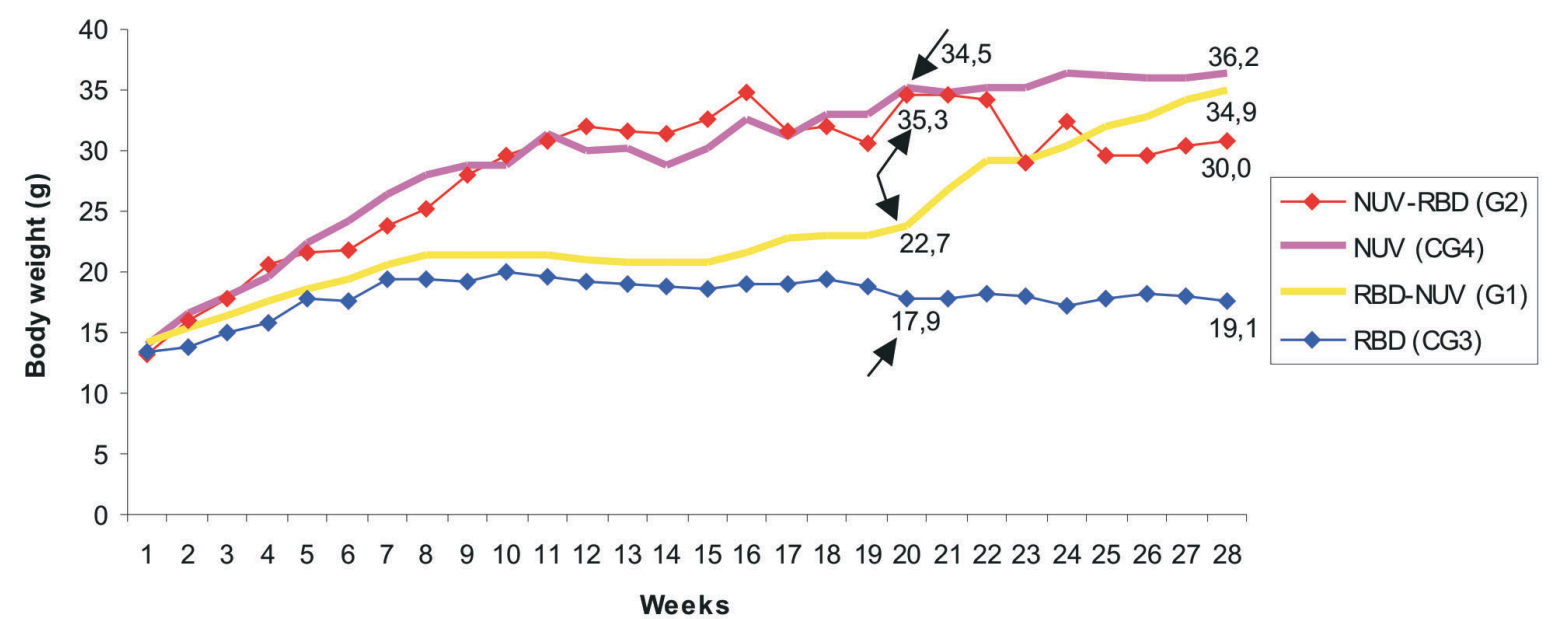

Fig.1: body weigth of mice infected with Schistosoma mansoni, submitted to early (G-1) and/or late undernutrition (G-2), as compared to their respective controls (CG-3 and CG-4). Arrows indicate the mean body weight of the mice at the time point of diet shifting, in groups G-1 and G-2; and the evolution of the growth curves from this time point onward, in "long-lasting" undernourished (CG-3) and "longlasting" normally fed (CG-4) control groups, for comparison.

various groups and their significance are depicted on Table I.

Histopathology - The histologic picture of the liver presented by the animals fed on deficient diet during 28 weeks (Group CG-3) did not substantially differ when the restricted diet was shifted to a well-balanced diet for 8 weeks (Group G-1). The aspects presented by both groups of mice included scattered discrete periovular granulomas, with variable amount of peri-sinusoidal and septal fibrosis (Fig. 2). Signs of non-specific reactional hepatitis, represented by infiltrations of mononuclear leukocytes admixed with few polymorphonuclear eosinophils within portal spaces and around central veins were absent or mild. Instead, a few isolated foci of ischemic necrosis or moderate fatty changes were sometimes observed. No instance of portal concentration of granulomas, associated with portal expansion and fibrotic connections between portal spaces ("pipestem" fibrosis) was recorded.

Well-nourished animals (Group CG-4) also presented scattered, discrete periovular granulomas of different sizes and cellular composition. In some, there was a large amount of lymphocytes and eosinophils, while in others fibroblasts and macrophages predominated. Although some concentration of granulomas in portal spaces was frequently observed, no clear-cut picture of "pipestem" fibrosis was observed. Reactive hepatitis was sometimes prominent. Besides focal cellular infiltrations in portal, parenchymal, and centrolobular areas, there were foci of coagulative necrosis and periportal or diffuse fatty changes. Eight weeks after the animals changed to a deficient diet (Group G-2), the histologic picture underwent mild to moderate changes. Then, several granulomas appeared large, round, with fusiform cells within a loose fibrilar matrix and the signs of non-reactive hepatitis subsided (Fig. 3). However, the changes of pipestem fibrosis were detected in two mice belonging to the "late undernourished" group.

Morphometric analysis - The volume density of periovular granulomas was high in well-nourished control mice and in those submitted to "late undernutrition" (Fig. 4). The numerical density was low in undernourished controls and in those submitted to "early malnutrition" (Fig. 5). The mean size of periovular granulomas was also significantly high for groups CG4 (control) and G2.

Hepatic fibrosis diminished in "early undernourished" mice when measured morphometrically as percentage of

TABLE I

Body and organ weight ratio (liver, spleen) from Schistosoma mansoni infected mice submitted to early and/or late undernutrition, in comparison to controls

\begin{tabular}{lcccc}
\hline $\begin{array}{l}\text { Experimental } \\
\text { groups }\end{array}$ & Nr of mice & $\begin{array}{c}\text { Liver wt/body wt ratio (\%) } \\
\text { Mean } \pm \text { Sem }\end{array}$ & $\begin{array}{c}\text { Spleen wt/bodywt ratio (\%) } \\
\text { Mean } \pm \text { Sem }\end{array}$ & $\begin{array}{c}\text { Significance } \\
\mathrm{p}<0.05\end{array}$ \\
\hline G-1 & 11 & $5.81 \pm 0.24$ & $0.66 \pm 0.06$ & G1 x G2 ${ }^{a}$ \\
G-2 & 11 & $4.82 \pm 0.23$ & $0.53 \pm 0.04$ & G1 x CG3 ${ }^{a}$ \\
CG-3 & 7 & $4.46 \pm 0.32$ & $0.43 \pm 0.06$ & G1 $^{x}$ CG3 \\
CG-4 & 11 & $5.86 \pm 0.13$ & $0.63 \pm 0.04$ & G2 $^{a}$ CG4 \\
\hline
\end{tabular}

Sem: standard error of the mean; G-1: early undernutrition; G-2: late undernutrition; C-G3: long- lasting undernutrition (Control G1); C-G4: long- lasting normal feeding (Control G-2); $a$ : significant difference for liver/body weight ratio; $b$ : significant difference for spleen/body weight ratio 
hepatic tissue $(11.1 \pm$ SEM 1.45 in $\mathrm{G} 1$ and $23.6 \pm \mathrm{SEM} 2.71$ in G2).

Biochemical study - Hydroxyproline levels were reduced in the "early undernourished" group (10.24 \pm SEM $1.55)$ as compared to "late undernourished" mice $(6.99 \pm$ SEM 1.53). The amount of hepatic fibrous tissue did not correlate with the number of eggs present in the liver. The mean number of eggs per total liver and the respective standard error of the mean were $16.33 \pm 2.37$ (G1), $43.98 \pm$ 7.54 (G2), $21.66 \pm 1.77$ (CG3), and 24.79 \pm 4.46 (CG4). There was good correlation between data related to total hepatic fibrosis by both morphometric and biochemical methods (Table II).

\section{DISCUSSION}

Previous investigation has demonstrated that mice maintained on a deficient protein diet and submitted to a mild and prolonged infection with $S$. mansoni failed to develop a morphologic picture of "pipestem periportal fibrosis, while $30-50 \%$ of well-nourished controls did (Coutinho et al. 1997). As a matter of fact, malnutrition decreases several parameters of the immuno-pathological response. However, the overall hepatic histologic picture observed in murine schistosomiasis was apparently not affected by the shifting of diets, either from a deficient to a balanced or vice-versa. It seems that, once the modulation of the early acute changes has occurred, the anatomic pattern of chronic schistosomiasis becomes more stable. This came to be the main and somewhat unexpected finding of the present investigation.

The fact that pipestem fibrosis has been recorded in two animals in the group G2 ("late malnutrition") but in none of the group G1 ("early malnutrition") is not surprising. Probably the pipestem change occurred during the time a well-balanced diet was being fed. Then, shifting to a deficient diet was not sufficient to reverse the picture. But, why pipestem fibrosis was not observed in mice from the control group receiving adequate diet during the whole

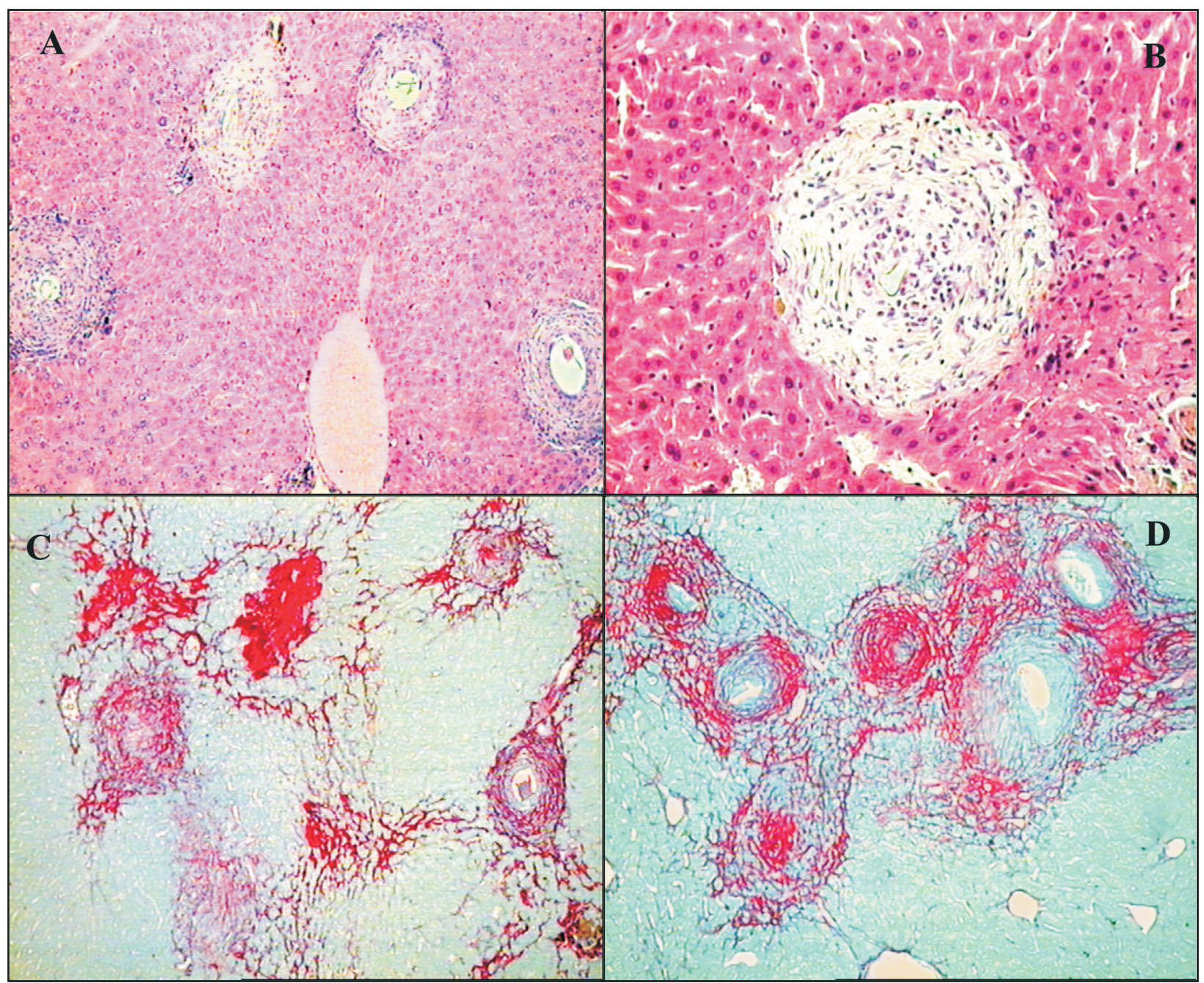

Fig. 2: "early undernutrition" (Group G-1), in mice infected with Schistosoma mansoni. A: scattered periovular granulomas on the background of a well-preserved liver architecture. Granulomas are in different evolutive stages, but all are small and discrete. Hematoxylin and Eosin (H \& E), X 100; B: a relatively large, clear, well-delimited, isolated, cell-rich involutive granuloma. H \& E, X 200; C and D: concentration of isolated granulomas, with mild degree of peri-granulomatous fibrosis forming portal to portal connections and simulating early "pipestem" fibrosis. Picro-syrius red method, $100 \mathrm{X}$ 
time of the experiment? A possible explanation rests on the relatively small number of animals used, coupled to the 30 to $50 \%$ chances of occurrence of pipestem fibrosis, as usually happens with the murine model (Andrade \& Cheever 1993).

The presence of conspicuous large fibrotic granulomas in animals of the "late undernourished" group may indicate they were formed when the animals were still well nourished, but failed to be degraded later on, when a deficient diet was used. Only further investigation can clarify how undernutrition can interfere with the process of fibrous resorption. The rate of collagen degradation depends on several known and unknown factors, among them on the interplay of collagenase and the tissue collagenase inhibitors (Truden \& Boros 1988), and on the degree of collagen maturation or "cross-linkings" (Ricard-

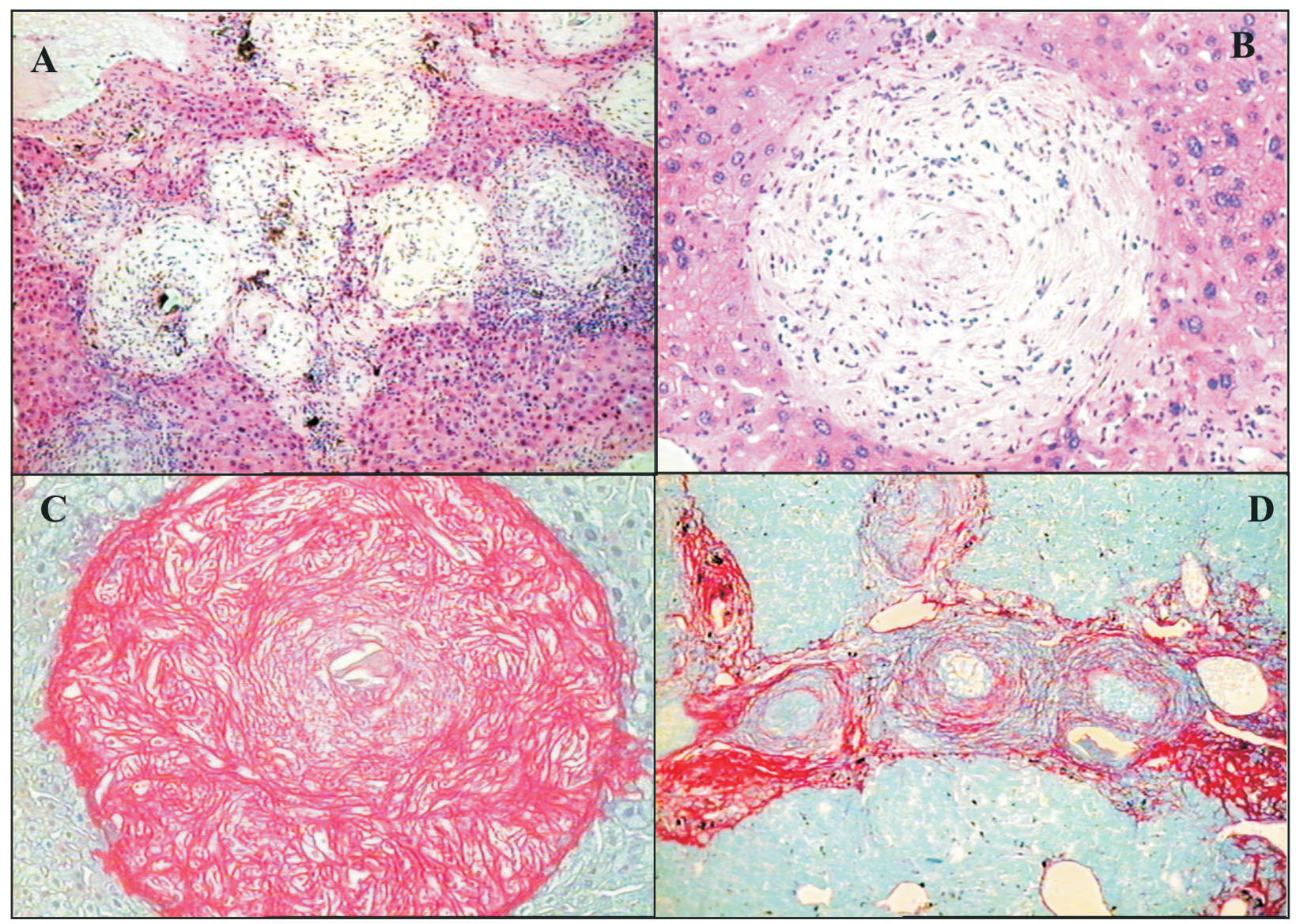

Fig. 3: "late undernutrition" (Group G-2), in mice infected with Schistosoma mansoni. A: the large, clear involutive granulomas are claustered within a portal space. Hematoxylin and Eosin (H \& E), 100X; B and C: the clear and large granuloma, frequently found in "late undernourished" mice, is shown in $\mathrm{H}$ \& E and Syrius-red staining, respectively, to illustrate their size, cellular distribution and collagen whorled disposition, $200 \mathrm{X}$; D: distribution of periovular granulomas within a portal space. The red-stained collagen forms a collar in the inner part of the granulomas, but contributes little to diffuse portal fibrosis. Picro-syrius red method, $100 \mathrm{X}$

TABLE II

Morphometric and biochemical evaluations on the amount of fibrous tissue (collagen ) present in the liver of Schistosoma mansoni infected mice submitted to either "early" and/or "late undernutrition" in comparison to controls

\begin{tabular}{|c|c|c|c|c|c|}
\hline $\begin{array}{l}\text { Experimental } \\
\text { groups }\end{array}$ & Nr of mice & $\begin{array}{c}\text { Percentage of } \\
\text { fibrous tissue } \\
\text { (morphomety) } \\
\text { Mean } \pm \text { Sem }\end{array}$ & $\begin{array}{l}\text { Significance } \\
\mathrm{P}<0.05\end{array}$ & $\begin{array}{c}\text { Hydroxyproline } \\
\text { Corrected for egg numbers } \\
\left(\mu \mathrm{mol} / \text { eggs } 10^{4}\right) \\
\text { Mean } \pm \text { Sem }\end{array}$ & $\begin{array}{l}\text { Significance } \\
\mathrm{p}<0.05\end{array}$ \\
\hline G-1 & 11 & $11.10 \pm 1.45$ & $\mathrm{G} 1 \times \mathrm{G} 2$ & $10.24 \pm 1.55$ & \\
\hline G-2 & 11 & $23.60 \pm 2.71$ & G1 x CG-3 & $6.99 \pm 1.53$ & G2 $x$ CG-4 \\
\hline CG-3 & 7 & $16.70 \pm 1.63$ & G1 x CG-4C & $5.07 \pm 1.92$ & $\mathrm{CG}-3 \times \mathrm{CG}-4$ \\
\hline CG-4 & 11 & $26.50 \pm 2.62$ & G-3 x G-4 & $15.5 \pm 3.41$ & \\
\hline
\end{tabular}

Sem: standard error of the mean; G-1: early undernutrition; G-2: late undernutrition; C-G3: long-lasting undernutrition (Control G-1); C-G4: long-lasting normal feeding (Control G2) 
Blum et al. 1992). All these steps involve protein synthesis, therefore being susceptible of interference by the nutritional status.

The indicators of protein nutritional status used in the present investigation have pointed to a major influence of the type of ingested diet (deficient or balanced) on the nutritional status of the mice, rather than of the S. mansoni infection. The same conclusion can be drawn regarding gross anatomical changes in liver and spleen. In the "early undernourished" group, the shifting from the deficient to the balanced diet in the second phase of the trial enhanced the storage of protein reserves in the liver, leading to a

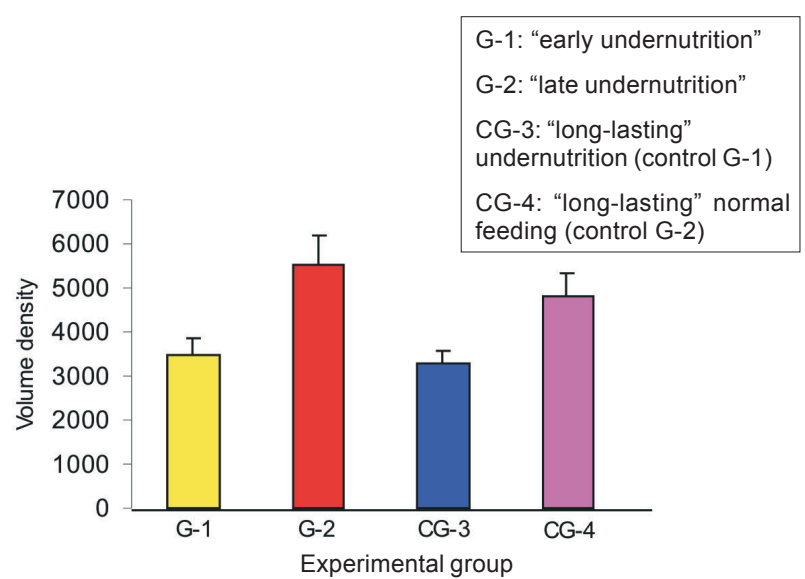

Fig. 4: volume density of periovular granulomas in undernourished and well-nourished mice infected with Schistosoma mansoni.

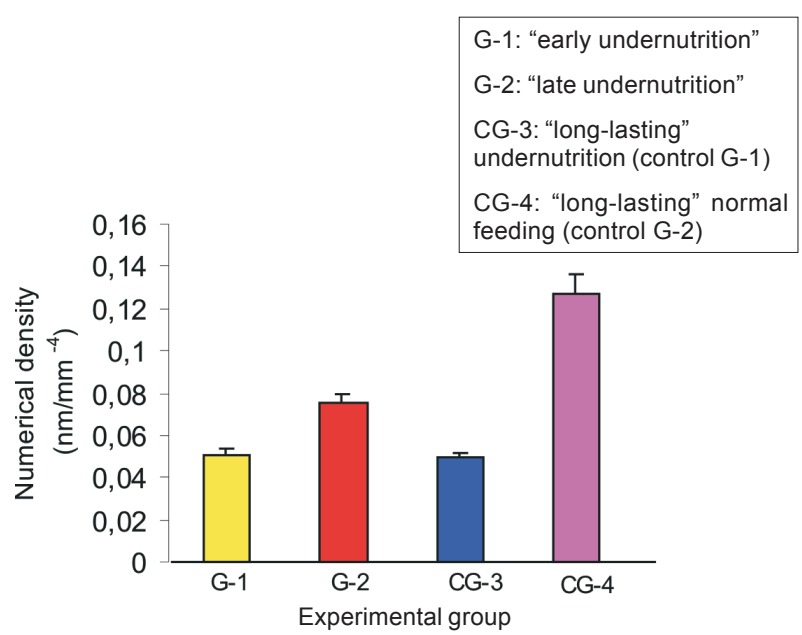

Fig. 5: numerical density of periovular granulomas in undernourished and well-nourished mice infected with Schistosoma mansoni.

significant increase in liver weight. Opposite results were obtained in the "late undernourished" group. Increase in spleen size, however, seemed to be due to the schistosomiasis infection, the nutritional status playing but an ancillary influence.

In this experiment, the degree of hepatic fibrous tissue in mice did not correlate with the number of eggs present in the liver, similarly as reported by Andrade and Cheever (1993).
On the other hand, the amount of hepatic collagen measured by both morphometric and biochemical methods, was reduced in undernourished mice, in agreement with the histopathological picture.

Present results indicated nutritional status of the host as a contributory factor in the remodeling of periovular granulomas of hepatic schistosomiasis. Therefore, schistosomal granuloma in undernourished mice may represent an adequate model for studies on the dynamics of hepatic fibrosis.

\section{REFERENCES}

Andrade ZA 1965. Hepatic schistosomiasis-morphological aspects. In H Popper, F Schaffner (eds), Progress in Liver Diseases, Vol. 2, Grune \& Stratton, New York, p. 228-242

Andrade ZA 1987. Pathogenesis of "pipestem" fibrosis of the liver (Experimental observation on murine schistosmiasis). Mem Inst Oswaldo Cruz 82: 325-334.

Andrade ZA, Bina JC 1983. A patologia da forma hepatoesplênica da esquistossomose mansoni em sua forma avançada (Estudo de 232 necropsias completas). Mem Inst Oswaldo Cruz 78: 285-305.

Andrade ZA, Cheever AW 1993. Characterization of the murine model of schistosomal hepatic periportal fibrosis ("pipestem" fibrosis). Int J Exp Pathol 74: 195-202.

Andrade ZA, Silva LM, Souza MM 1997. An experimental approach to the pathogenesis of "pipestem" fibrosis (Symmer's fibrosis of the liver). Mem Inst Oswaldo Cruz 92: 699-706.

Barbosa Jr AA 2001. Morphological computer-assisted quantitative estimation of stained fibrous tissue in liver sections: applications in diagnosis and experimental research. J Bras Patol 37: 197-200.

Bergman I, Loxley R 1963. Two improved and simplified methods for the spectrophotometric determination of hydroxyproline. Ann Chem 35: 1961-1965.

Bogliolo L 1957. Anatomical picture of the liver in hepatosplenic schistosomiasis mansoni. Ann Trop Med Parasitol 51: 114.

Cheever AW 1970. Relative resistance of the eggs of human schistosomes to digestion in potassium hydroxide. Bull WHO 43: 601-603.

Cheever AW, Duvall RH, Minker RG, Nash JE 1980 Hepatic fibrosis in rabbits infected with Japanese and Philippine strains of Schistosoma japonicum. Am J Trop Med Hyg 29: 1327-1339.

Cheever AW, Duvall RH, Hallack Jr TA, Minker RG, Malley JD, Malley KG 1987. Variation of hepatic fibrosis and granuloma size among mouse strains infected with Schistosoma mansoni. Am J Trop Med Hyg 37: 85-97.

Coutinho EM 1980. Patobiologia da desnutrição nas doenças parasitárias. Mem Inst Oswaldo Cruz 75: 63-76.

Coutinho EM, Freitas LPCG, Abath FGC 1992. The influence of the regional basic diet from Northeast Brazil on health and nutritional conditions of mice infected with Schistosoma mansoni. Rev Soc Bras Med Trop 25: 13-20

Coutinho EM, Souza MM, Silva LM, Cavalcanti CL, Araújo RE, Barbosa Jr AA, Cheever AW, Andrade ZA 1997. Pathogenesis of schistosomal "pipestem" fibrosis: a lowprotein diet inhibits the development of "pipestem" fibrosis in mice. Inst J Exp Pathol 78: 337-342.

Henderson GS, Nix NA, Montesano MA, Gold D, Freeman Jr GL, McCurley TL, Colley DG 1993. Two distinct pathological syndromes in male CBA/J inbred nice with chronic Schistosoma mansoni infections. Am J Pathol 142: 703713. 
Junqueira LCU, Bignolas G, Brentani R 1979. Picrosirius staining plus polarization microscopy, a specific method for collagen detection in tissue section. Histochem $J 11$ : 447-455.

Lichtenberg FV, Sadun EH, Cheever AW, Erickson DG, Johnson AJ, Boyce HW 1971. Experimental infection with Schistosoma japonicum in chimpanzees. Parasitologic, clinical, serologic and pathological observations. Am J Trop Med Hyg 20: 850-893.

Prata A, Andrade ZA 1963. Fibrose hepática de Symmers sem esplenomegalia. O Hospital 63: 617-623.

Ricard-Blum S, Ville G, Grimaud JA 1992. Pyridinoline, a mature collagen cross link, in fibrotic liver from Schistosoma mansoni-infected mice. Am J Trop Med Hyg 47: 816-820.

Sadun EH, Lichtenberg FV, Cheever AW, Erickson DG 1970. Schistosomiasis mansoni in the chimpanzee. The natural history of chronic infections after single and multiple exposures. Am J Trop Med Hyg 19: 258-277.

Symmers W St C 1904. Note on a new form of liver cirrhosis due to the presence of the ova of Bilharzia haematobia. J Pathol Bacteriol 9: 237-239.

Teodósio NR, Lago ES, Romani SAM, Guedes RCA 1990. A regional basic diet from Northeast Brazil as a dietary model of experimental malnutrition. Arch Lat Amer Nutr 40: 533-547.

Truden JL, Boros DL 1988. Detection of $\propto 2$-macroglobulin, $\propto$-protease inhibitor, and neutral protease anti-protease complexes within liver granulomas of Schistosoma mansoni infected mice. Am J Pathol 130: 281-288.

Warren KS 1966. The pathogenesis of clay pipestem cirrhosis in mice with chronic schistosomiasis mansoni, with a note on the longevity of the schistosomes. Am J Pathol 49: 477489. 